\title{
The association of ABO blood group with the asymptomatic COVID-19 cases in India
}

Prajjval Pratap Singh ${ }^{1}$, Abhishek K Srivastava², Sudhir K Upadhyay ${ }^{3}$, Ashish Singh ${ }^{4}$, Pranav Gupta $^{5}$, Sanjeev Maurya ${ }^{4}$, Shashank Upadhyay6, Rudra Kumar Pandey ${ }^{1}$, Anshika Srivastava ${ }^{1}$, Priya Dev 7, Vanya Singh"1, Rahul Mishra1, Manoj Kumar Shukla ${ }^{8}$, Govind Chaubey ${ }^{9}$, Pradeep Kumar $^{10}$, Vandana Rai ${ }^{10}$, Yamini B Tripathi ${ }^{8}$, Abhishek Pathak ${ }^{7}$, Vijay Nath Mishra ${ }^{7}$, Chandana Basu Mallick ${ }^{11}$, Pankaj Shrivastava ${ }^{12}$ and Gyaneshwer Chaubey ${ }^{1}$

Prajjval Pratap Singh, Abhishek Shrivastava, Sudhir Upadhyay, and Ashish Singh - equal first author contribution

${ }^{1}$ Cytogenetics Laboratory Department of Zoology, Banaras Hindu University, India

${ }^{2}$ Mohd. Hasan P. G. College, Jaunpur, India

3Department of Environmental Science, Veer Bahadur Singh Purvanchal University, Jaunpur, India

${ }^{4}$ Genome Foundation Rural Centre Kalavari, Jaunpur, India, 222131

Independent researcher

6 Invertis University, Bareilly, Uttar Pradesh, India

7Department of Neurology, Institute of Medical Science, Banaras Hindu University, India

${ }^{8}$ Department of Medicinal Chemistry, Institute of Medical Science, Banaras Hindu University, India

${ }^{9}$ District Institute Of Education \& Training, Sarnath, Varanasi, 221007

${ }^{10}$ Department of Biotechnology, Veer Bahadur Singh Purvanchal University, Jaunpur, India

${ }^{11}$ Centre for Genetic Disorders, Banaras Hindu University, India

${ }^{12}$ DNA Fingerprinting Unit, State Forensic Science Laboratory, Department of Home (Police), Government of MP, Sagar, India

Correspondence: gyaneshwer.chaubey@bhu.ac.in or prajjval4777@gmail.com

Keywords: India, Blood group, Asymptomatic, COVID-19, Coronavirus 
medRxiv preprint doi: https://doi.org/10.1101/2021.04.01.21254681; this version posted April 6, 2021. The copyright holder for this preprint (which was not certified by peer review) is the author/funder, who has granted medRxiv a license to display the preprint in perpetuity.

It is made available under a CC-BY-NC-ND 4.0 International license.

\begin{abstract}
The COVID-19 pandemic has resulted several waves of infection in many countries worldwide. The large variations in case fatality ratio among different geographical regions suggests that the human susceptibility against this virus varies substantially. Several studies from different parts of the world showed a significant association of ABO blood group and COVID-19 susceptibility. It was shown that individuals with blood group 0 are at the lower risk of coronavirus infection. To establish the association of ABO blood group in SARS-CoV-2 susceptibility, we for the first time analysed SARS-CoV2 neutralising antibodies as well as blood groups among 509 random individuals from three major districts of Eastern Uttar Pradesh region of India. . Interestingly, we found neutralising antibodies in significantly higher percentage of people with blood group $A B$ (0.36) followed by B (0.31), A (0.22) and lowest in people with blood group 0 (0.11). This indicates that people with blood group $\mathrm{AB}$ are at comparatively higher risk of infection than other blood groups. Further, in line to previous reports we too observed that people with blood group 0 have significantly decreased risk of SARS-CoV-2 infection. Thus, among the asymptomatic SARS-CoV-2 infected individuals with blood group $\mathrm{AB}$ has highest, whilst blood group 0 has lowest risk of infection.
\end{abstract}


medRxiv preprint doi: https://doi.org/10.1101/2021.04.01.21254681; this version posted April 6, 2021. The copyright holder for this preprint (which was not certified by peer review) is the author/funder, who has granted medRxiv a license to display the preprint in perpetuity. It is made available under a CC-BY-NC-ND 4.0 International license .

\section{Introduction}

COVID-19 has impacted life of billions because of its detrimental nature. With extensive and ongoing research, we are slowly understating the nature of this novel SARS-CoV-2 virus first time transmitted to the humans ${ }^{1-6}$. With the growing knowledge about this disease, it is clear that there are certain risk factors associated with morbidity and mortality ${ }^{7-9}$. More importantly, several of the studies have found strong association of the ABO blood group and COVID-19 with morbidity and mortality 6,10-14. In the past, there have been several studies on the association of $\mathrm{ABO}$ blood group with the diseases. For example, individual with the blood group 0 were reported to be more susceptible to the Cholera in Gangetic plain populations 15 and Helicobacter pylori infection ${ }^{16}$. However, blood group 0 was found to be less susceptible for Dengue 17,18 and SARS (Severe Acute Respiratory Syndrome) viruses ${ }^{14,19}$.

The ABO blood type is administered by the gene $A B O$, present at chromosome 920 . Studies have found that the this gene modulates the COVID-19 susceptibility directly or indirectly ${ }^{21-23}$. Several variants of this gene affect morbidity and mortality in COVID-19 and many other diseases. For example, it affects red blood related physiology 24,25, venous thromboembolism ${ }^{26}$, type 2 diabetes ${ }^{27}$, ischemic stroke ${ }^{28}$, heart related functions ${ }^{29}$ and coronary artery disease ${ }^{29-31}$. Thus, investigating the association of $A B O$ blood type with SARS-CoV-2 infection, it is feasible to ascertain the factors affecting the susceptibility against SARS-CoV-2 in humans.

In the present study, we sought to investigate the association between asymptomatic COVID-19 positive people with their blood types using random serosurvillance and blood group testing of street vendors in northern India.

\section{Materials and Method}

In our survey, we used two commercially available kits Coviscreen ${ }^{\mathrm{TM}}$ and ERYCARD ${ }^{\mathrm{TM}}$ 2.0 to determine the seropositivity and the blood groups respectively. Theses kits were kind gift by Biosense Technologies, India. Similar to our previous work ${ }^{32}$, we focussed on the urban populations in our survey. A total of 509 healthy individuals were screened for both the tests. The participants were between the age of 18-65 years from the three districts of the Eastern Uttar Pradesh state (Supplementary Fig. 1). We focussed on the urban healthy vendors who have neither been diagnosed with COVID- 
medRxiv preprint doi: https://doi.org/10.1101/2021.04.01.21254681; this version posted April 6, 2021. The copyright holder for this preprint (which was not certified by peer review) is the author/funder, who has granted medRxiv a license to display the preprint in perpetuity. It is made available under a CC-BY-NC-ND 4.0 International license .

19 , nor had been sick with any associated symptoms in the recent past. We excluded those individuals whose family members had ever been diagnosed with COVID-19. This study was conducted between months of September 2020 to October 2020. The aim of the study was explained to the people and informed consent were obtained. This study was approved by the ethical committee of Banaras Hindu University, Varanasi, India.

Both COVID-19 and blood group testing were done using manufacturer's instructions provided in the kit. A sample test of Coviscreen ${ }^{\mathrm{TM}}$ and ERYCARD ${ }^{\mathrm{TM}} 2.0$ has been shown in Supplementary Fig. 2. The frequency of seropositive and blood groups were calculated (Supplementary Table 1). The frequency bar plot of each blood group was drawn with 95\% CI (Figure 1). We have also collected blood group data of the same region for comparison from published sources ${ }^{33-40}$.

The data was analysed using two tailed Chi square test. Odds ratio (OR) and 95\% Confidence interval (CI) were calculated (Table 1 and Supplementary Table 2). Statistical computations were performed using SPSS (ver. 25).

\section{Results and discussion}

We collected data of seroprevalence as well as blood group affiliation among 509 individuals from three districts of Eastern Uttar Pradesh region (Supplementary Table 1). The seroprevalence among all the studied districts was $>0.4$. The high level of seroprevalence among these districts suggests a hidden undercurrent wave of infection mainly driven by asymptomatic individuals. It is imperative to stress that, this is not the story of a particular region of India. Remarkably, other independent regions in the country have also demonstrated a high level of seroprevalence ${ }^{41,42}$. Nevertheless, it is not uniform, rather sporadic.

In the collection of random 509 samples, we found a frequency distribution of 0.204 , $0.354,0.279$ and 0.163 for blood groups A, B, O and AB respectively (Supplementary Table 1). Blood group B is most common blood group followed by blood group 0 , whereas blood group $\mathrm{AB}$ is least common among the populations of Eastern Uttar Pradesh region. To test if our sampling covered a true blood group distribution of this region, we have collected the published data of the same region ${ }^{33-40}$ and performed a regression analysis. The adjusted $\mathrm{R}$ square value $(96.7 \% \pm 2.7 \%)$ showed a significantly 
medRxiv preprint doi: https://doi.org/10.1101/2021.04.01.21254681; this version posted April 6, 2021. The copyright holder for this preprint (which was not certified by peer review) is the author/funder, who has granted medRxiv a license to display the preprint in perpetuity. It is made available under a CC-BY-NC-ND 4.0 International license .

high level of correlation between our data as well as published data, suggesting that our sampling indeed captured the regional distribution of the blood groups.

We further grouped COVID-19 positive samples and estimated their ABO blood group division. The 215 seropositive individuals showed their ABO blood group distribution of $0.223,0.312,0.107$ and 0.358 for $\mathrm{A}, \mathrm{B}, \mathrm{O}$ and $\mathrm{AB}$ blood groups respectively (Supplementary Table 1). The relative comparison of blood group distribution have shown large discrepancy for the blood groups 0 and $A B$ (Fig. 1). Blood group AB was significantly higher, whereas blood group 0 was significantly lower among seropositive group ( $\mathrm{p}<0.001$ ) (Table 1). This result was also consistent with the comparison of seropositive individuals with the published data (Supplementary Fig. 3 and Supplementary Table 1). This suggested strong association of blood groups 0 and $\mathrm{AB}$ with COVID-19 susceptibility. The risk estimation revealed several fold higher risk of infection to blood group $\mathrm{AB}$ and lower risk for blood group 0 type (Table 1 and Supplementary Table 2). On the risk scale, our investigation suggested blood group AB at the maximum, followed by blood group $\mathrm{A}$ and $\mathrm{B}$, whereas blood group $\mathrm{O}$ had lowest.

We would like to stress that our data does not include COVID-19 severe patients, due to our sampling methodology. Thus, it limits us to understand the association of blood group with the COVID-19 severity. On the other hand, it is highly enriched for the asymptomatic patients. Therefore, our result can also infer an important insight that, though blood group $\mathrm{AB}$ has the highest risk of infection, it may not have high risk of severity. The large number of hospital data will be able to testify it further.

It has been shown recently that the Rh negative blood type has a protective role against SARS-CoV-2 ${ }^{12}$. We have tested this association and found out 0.333 (95\% CI 0.152 0.587 ) seroprevalence for $\mathrm{Rh}$ negative individuals, which is not significantly different than $0.425(95 \%$ CI $0.382-0.469)$ seroprevalence of $\mathrm{Rh}$ positive people ( $\mathrm{p}>0.05)$ (Supplementary Table 2). Thus, we did not find any association of Rh factor with COVID19. However, the limited sample size (15), of $\mathrm{Rh}$ negative individuals should be taken with caution.

In summary, this is the first study in our knowledge which has been done on association of ABO locus with the COVID-19 susceptibility in India using asymptomatic COVID-19 positive individuals. Consistent with the previous observations, we have also found that 
the blood group 0 has least risk. However, we did not find any higher risk for blood group A as reported earlier, rather we see severalfold increased risk of infection for blood group AB. With our novel sampling methodology, we have also able to deduce that though blood group AB is highly susceptible for SARS-CoV-2 infection, it is unlike for them to develop disease severity.

\section{Acknowledgements}

We are grateful to the Biosense Technologies, India for their kind help in the seroprevalence project. We did not receive any specific funding for this work.

\section{Author Contributions}

GC conceived and designed this study. PPS, AKS, AS, PG, SM, SU, RKP, ANS, PD, VS, RM, MS, GOC, PK, VR, YBT, AP, VNM, CBM, PS and GC have collected the field data and performed the antibody as well as blood group testing. PPS and GC analysed the data. PPS, AKS, AS, PG, CBM and GC wrote the manuscript from the inputs of all co-authors. All authors contributed to the article and approved the submitted version.

\section{Data Availability Statement}

All datasets generated for this study are included in the article/Supplementary Material.

\section{Competing interests}

The authors declare no competing interests.

\section{Conflict of Interest}

Authors declare that the research was conducted in the absence of any commercial or financial relationships that could be construed as a potential conflict of interest. 
medRxiv preprint doi: https://doi.org/10.1101/2021.04.01.21254681; this version posted April 6, 2021. The copyright holder for this preprint (which was not certified by peer review) is the author/funder, who has granted medRxiv a license to display the preprint in perpetuity.

It is made available under a CC-BY-NC-ND 4.0 International license .

\section{References}

1. Aleta, A. et al. Modelling the impact of testing, contact tracing and household quarantine on second waves of COVID-19. Nat. Hum. Behav. 4, 964-971 (2020).

2. Alberca, R. W., Oliveira, L. de M., Branco, A. C. C. C., Pereira, N. Z. \& Sato, M. N. Obesity as a risk factor for COVID-19: an overview. Crit. Rev. Food Sci. Nutr. 1-15 (2020).

3. Batiha, O., Al-Deeb, T., Al-zoubi, E. \& Alsharu, E. Impact of COVID-19 and other viruses on reproductive health. Andrologia 52, e13791 (2020).

4. Day, M. Covid-19: identifying and isolating asymptomatic people helped eliminate virus in Italian village. Bmj 368, m1165 (2020).

5. Andersen, K. G., Rambaut, A., Lipkin, W. I., Holmes, E. C. \& Garry, R. F. The proximal origin of SARS-CoV-2. Nat. Med. 26, 450-452 (2020).

6. Zietz, M., Zucker, J. \& Tatonetti, N. P. Associations between blood type and COVID-19 infection, intubation, and death. Nat. Commun. 11, 1-6 (2020).

7. Wang, T. et al. Comorbidities and multi-organ injuries in the treatment of COVID-19. The Lancet 395, e52 (2020).

8. Yang, J. et al. Prevalence of comorbidities in the novel Wuhan coronavirus (COVID19) infection: a systematic review and meta-analysis. Int. J. Infect. Dis. (2020).

9. Chaubey, G. Coronavirus (SARS-CoV-2) and Mortality Rate in India: The Winning Edge. Front. Public Health 8, 397 (2020).

10. AL-Khikani, F. H. O. The role of blood group in COVID-19 infection: More information is needed. J. Nat. Sci. Med. 3, 225 (2020).

11. Dai, X. ABO blood group predisposes to COVID-19 severity and cardiovascular diseases. Eur. J. Prev. Cardiol. 27, 1436-1437 (2020).

12. Esref, A. et al. Association between the Rh blood group and the Covid-19 susceptibility. Int. J. Hematol. Oncol. 30, 081-086 (2020). 
13. Göker, H. et al. The effects of blood group types on the risk of COVID-19 infection and its clinical outcome. Turk. J. Med. Sci. 50, 679-683 (2020).

14. Padhi, S. et al. ABO blood group system is associated with COVID-19 mortality: an epidemiological investigation in the Indian population. Transfus. Clin. Biol. 27, 253$258(2020)$.

15. Glass, R. I. et al. Predisposition for cholera of individuals with 0 blood group possible evolutionary significance. Am. J. Epidemiol. 121, 791-796 (1985).

16. Lin, C.-W., Chang, Y.-S., Wu, S.-C. \& CHENG, K.-S. Helicobacter pylori in gastric biopsies of Taiwanese patients with gastroduodenal diseases. Jpn. J. Med. Sci. Biol. 51, 13-23 (1998).

17. Hashan, M. R. et al. Association of dengue disease severity and blood group: A systematic review and meta-analysis. Rev. Med. Virol. 31, 1-9 (2021).

18. Kalayanarooj, S. et al. Blood group AB is associated with increased risk for severe dengue disease in secondary infections. J. Infect. Dis. 195, 1014-1017 (2007).

19. Fan, Q. et al. Association between ABO blood group system and COVID-19 susceptibility in Wuhan. Front. Cell. Infect. Microbiol. 10, (2020).

20. Ellinghaus, D. et al. The ABO blood group locus and a chromosome 3 gene cluster associate with SARS-CoV-2 respiratory failure in an Italian-Spanish genome-wide association analysis. MedRxiv (2020).

21. Ellinghaus, D. et al. Genomewide association study of severe Covid-19 with respiratory failure. N. Engl. J. Med. (2020).

22. Cordero, A. I. H. et al. Multi-omics highlights ABO plasma protein as a causal risk factor for COVID-19. Hum. Genet. 1-11 (2021).

23. Yamamoto, F., Yamamoto, M. \& Muñiz-Diaz, E. Blood group ABO polymorphism inhibits SARS-CoV-2 infection and affects COVID-19 progression. Vox Sang. (2020). 
24. Kamatani, Y. et al. Genome-wide association study of hematological and biochemical traits in a Japanese population. Nat. Genet. 42, 210 (2010).

25. Astle, W. J. et al. The allelic landscape of human blood cell trait variation and links to common complex disease. Cell 167, 1415-1429 (2016).

26. Germain, M. et al. Meta-analysis of 65,734 individuals identifies TSPAN15 and SLC44A2 as two susceptibility loci for venous thromboembolism. Am. J. Hum. Genet. 96, 532-542 (2015).

27. Xue, A. et al. Genome-wide association analyses identify 143 risk variants and putative regulatory mechanisms for type 2 diabetes. Nat. Commun. 9, 1-14 (2018).

28. Malik, R. et al. Multiancestry genome-wide association study of 520,000 subjects identifies 32 loci associated with stroke and stroke subtypes. Nat. Genet. 50, 524537 (2018).

29. Nikpay, M. et al. A comprehensive 1000 Genomes-based genome-wide association meta-analysis of coronary artery disease. Nat. Genet. 47, 1121 (2015).

30. Schunkert, H. et al. Large-scale association analysis identifies 13 new susceptibility loci for coronary artery disease. Nat. Genet. 43, 333-338 (2011).

31. CARDIoGRAMplusC4D Consortium et al. Large-scale association analysis identifies new risk loci for coronary artery disease. Nat. Genet. 45, 25-33 (2013).

32. Singh, P. P. et al. Estimation of real-infection and immunity against SARS-CoV-2 in Indian populations. medRxiv (2021).

33. Agarwal, N., Thapliyal, R. M. \& Chatterjee, K. Blood group phenotype frequencies in blood donors from a tertiary care hospital in north India. Blood Res. 48, 51 (2013).

34. Kumar, P. \& Rai, V. Prevalence of Blood Groups in Eastern UP Population. (2020).

35. Kumar, P. \& Rai, V. Prevalence of of ABO and Rhesus (Rh) Blood Groups in Eastern UP Population. bioRxiv (2020). 
36. Kumar, P., Singh, V. K. \& Rai, V. Study of ABO and Rh (D) Blood Groups in Kshatriya (Rajput) of Jaunpur District, Uttar Pradesh. The Anthropologist 11, 303-304 (2009).

37. Kumar, P., Maurya, S. \& Rai, V. Distribution of ABO and Rh (D) blood groups among Koari (Backward Caste) population of Jaunpur district. The Anthropologist 11, 309310 (2009).

38. Kumar, P., Saima, S. \& Rai1, V. Study of ABO and Rh (D) blood groups in Sunni Muslims of Jaunpur District, Uttar Pradesh, India. The Anthropologist 12, 225-226 (2010).

39. Vandana, R. A. I. \& KUMAR, P. Genetic analysis of ABO and Rh blood groups in backward caste population of Uttar Pradesh, India. Not. Sci. Biol. 3, 07-14 (2011).

40. Rai, V. \& Kumar, P. The incidence of ABO blood group in Muslim population of Uttar Pradesh, India. J Appl Biosci 36, 191-195 (2010).

41. Murhekar, M. V. et al. SARS-CoV-2 antibody seroprevalence in India, AugustSeptember, 2020: findings from the second nationwide household serosurvey. Lancet Glob. Health 9, e257-e266 (2021).

42. Murhekar, M. V. et al. Prevalence of SARS-CoV-2 infection in India: Findings from the national serosurvey, May-June 2020. Indian J. Med. Res. 152, 48 (2020). 


\section{Figure Legends}

Figure 1. The comparative bar-plot of various blood groups among studied groups. The error bars have been calculated at $95 \%$ confidence interval.

Supplementary Figure 1. The sampling locations in the Eastern Uttar Pradesh.

Supplementary Figure 2. The sample test of seropositive and blood group of an individual.

Supplementary Figure 3. The comparative bar-plot of various blood groups observed in present study as well as collected from published data. The error bars have been calculated at $95 \%$ confidence interval.

Table 1. Various statistical tests on our data to infer the association and risk of ABO blood group for COVID-19. OR= Odds Ratio, CI= Confidence interval

\begin{tabular}{|l|cccc|}
\hline & A & B & AB & O \\
\hline Chi square & 0.632 & 2.564 & 101.331 & 53.276 \\
p value & 0.427 & 0.109 & $<0.001$ & $<0.001$ \\
OR & 1.222 & 0.725 & 26.783 & 0.176 \\
$95 \% \mathrm{Cl}$ & $0.792-1.884$ & $0.500-1.052$ & $11.3888-62.986$ & $10.108-0.288$ \\
\hline
\end{tabular}

Supplementary Table 1. The distribution of ABO blood groups among various cohorts used in this study

\begin{tabular}{|c|c|c|c|c|c|c|c|c|}
\hline & $\mathbf{N}$ & At & $\mathrm{B}+$ & $0+$ & $\mathrm{AB}+$ & A. & B. & 0 . \\
\hline All Samples & 509 & $0.198(0.166-0.235)$ & $0.34(0.3-0.382)$ & $0.269(0.232-0.309)$ & $0.163(0.134-0.198)$ & $0.006(0.002-0.017)$ & $0.014(0.007-0.028)$ & $0.010(0.004-0.023)$ \\
\hline Seropositive & 215 & $0.214(0.164-0.274)$ & $0.298(0.241-0.362)$ & $0.107(0.073-0.155)$ & $0.358(0.297-0.424)$ & $0.009(0.003-0.033$ & $0.014(0.005-0.04)$ & $0(0-0.017)$ \\
\hline & $\mathrm{N}$ & A & B & 0 & $A B$ & & & \\
\hline All Samples & 509 & $0.204(0.172-0.242)$ & $0.354(0.313-0.396)$ & $0.279(0.242-0.320)$ & $0.163(0.134-0.198)$ & & & \\
\hline Seropositive & 215 & $0.223(0.173-0.284)$ & $0.312(0.253-0.376)$ & $0.107(0.073-0.155)$ & $0.358(0.297-0.424)$ & & & \\
\hline Published Samples & 2272 & $0.239(0.222-0.257)$ & $0.375(0.356-0.396)$ & $0.297(0.278-0.316)$ & $0.089(0.078-0.101)$ & & & \\
\hline
\end{tabular}


Supplementary Table 2. Various statistical tests on our and published data to infer the association and risk of $\mathrm{ABO}$ blood group for COVID-19. OR= Odds Ratio, $\mathrm{CI}=$ Confidence interval.

\begin{tabular}{|l|ccccc|}
\hline & A & B & AB & O & Rh \\
\hline Chi square & 0.189 & 3.163 & 140.255 & 34.099 & 0.048 \\
p value & 0.664 & 0.075 & $<0.001$ & $<0.001$ & 0.827 \\
OR & 0.915 & 0.753 & 5.718 & 0.284 & 1.275 \\
$95 \% \mathrm{Cl}$ & $0.655-1.280$ & $0.557-1.017$ & $4.177-7.827$ & $0.183-0.442$ & $0.458-3.554$ \\
\hline
\end{tabular}


0.4

0.35

0.3

0.25

0.2

0.15

0.1

0.05

0

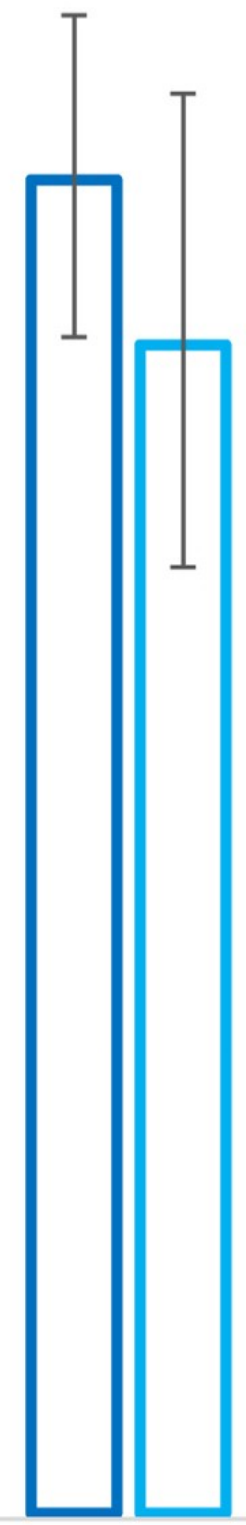

B+

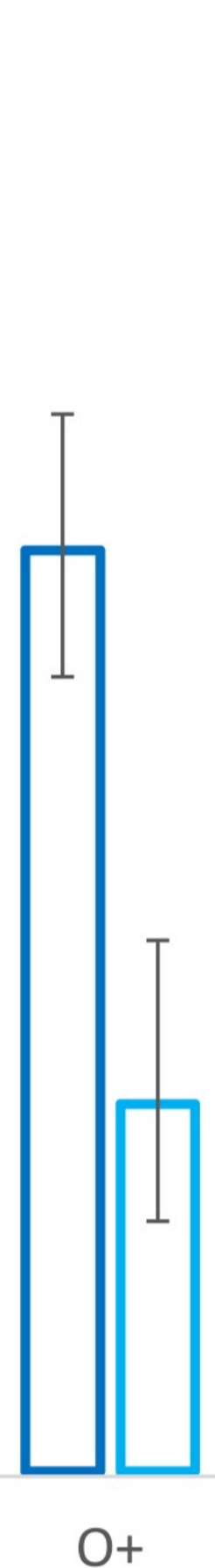

$\mathrm{O}+$

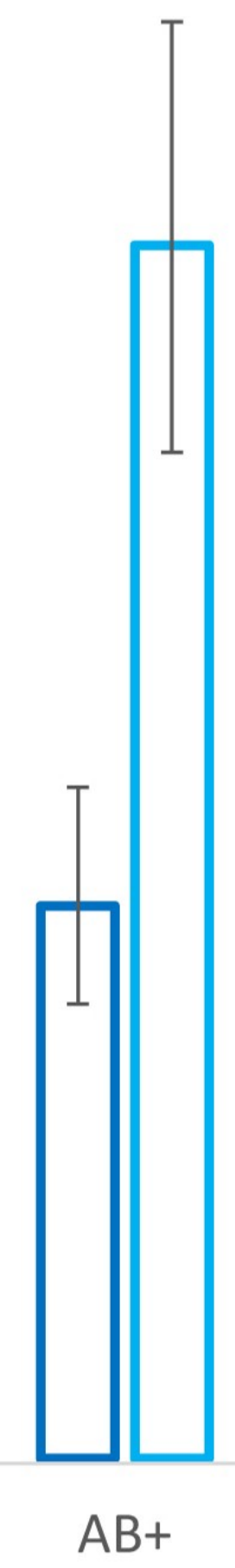

而

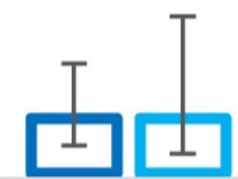

A- $\square$ All Samples

Seropositive

$$
\text { A+ }
$$

